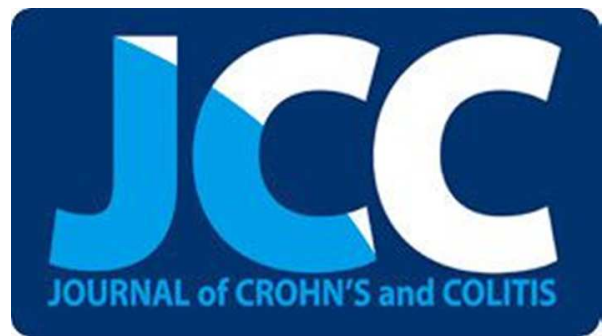

\title{
Correlation between endoscopic and histological activity in ulcerative colitis using validated indices
}

\begin{tabular}{|r|l|}
\hline Journal: & Journal of Crohn's and Colitis \\
\hline Manuscript ID & Draft \\
\hline Manuscript Type: & Original Article \\
\hline Date Submitted by the Author: & n/a \\
\hline Complete List of Authors: & $\begin{array}{l}\text { Irani, Nazneen; John Radcliffe Hospital, Translational Gastroenterology Unit } \\
\text { Wang, Lai Mun; John Radcliffe Hospital, Department of Cellular Pathology } \\
\text { Collins, Gary; University of Oxford, Centre for Statistics in Medicine } \\
\text { Keshav, Satish; John Radcliffe Hospital, Translational Gastroenterology Unit } \\
\text { Travis, Simon; John Radcliffe Hospital, Translational Gastroenterology Unit }\end{array}$ \\
\hline Subject: & Biomarkers, Endoscopy, Pathology \\
\hline Classifications: & Endoscopy, Biomarkers, Pathology \\
\hline & \multicolumn{2}{|l}{} \\
\hline
\end{tabular}




\begin{tabular}{|c|c|}
\hline Journal: & Journal of Crohn's and Colitis \\
\hline Article type: & Original Article \\
\hline Title : & $\begin{array}{l}\text { Correlation between endoscopic and histological activity in ulcerative } \\
\text { colitis using validated indices }\end{array}$ \\
\hline $\begin{array}{r}\text { Corresponding } \\
\text { Author: }\end{array}$ & $\begin{array}{l}\text { Professor Simon PL Travis } \\
\text { Translational Gastroenterology Unit, } \\
\text { John Radcliffe Hospital, } \\
\text { Oxford OX3 9DU, United Kingdom } \\
\text { Email: simon.travis@,ndm.ox.ac.uk } \\
\text { Phone: +441865228753 }\end{array}$ \\
\hline List of Authors: & $\begin{array}{l}\text { Irani, Nazneen R; Translational Gastroenterology Unit, } \\
\text { John Radcliffe Hospital, Oxford OX3 9DU, United Kingdom } \\
\text { Wang, Lai Mun; Department of Cellular Pathology, } \\
\text { John Radcliffe Hospital, Oxford OX3 9DU, United Kingdom } \\
\text { Collins, Gary S; Centre for Statistics in Medicine, } \\
\text { University of Oxford, United Kingdom } \\
\text { Keshav, Satish; Translational Gastroenterology Unit, } \\
\text { John Radcliffe Hospital, Oxford OX3 9DU, United Kingdom } \\
\text { Travis, Simon P L; Translational Gastroenterology Unit, } \\
\text { John Radcliffe Hospital, Oxford OX3 9DU, United Kingdom }\end{array}$ \\
\hline Short Title: & Endoscopic and histological activity in ulcerative colitis \\
\hline $\begin{array}{l}\text { Conference } \\
\text { Presentation: }\end{array}$ & $\begin{array}{l}\text { European Crohn's and Colitis Organisation, Barcelona } 2017 \\
\text { Digestive Diseases Week, Chicago } 2017\end{array}$ \\
\hline Keywords: & $\begin{array}{l}\text { Ulcerative Colitis, UCEIS, Histopathology, Nancy Index, Robarts' } \\
\text { Histopathology Index }\end{array}$ \\
\hline $\begin{array}{r}\text { Word count: } \\
\text { Number of tables: } \\
\text { Number of figures: } \\
\text { Number of references: }\end{array}$ & $\begin{array}{l}2404 \\
4 \\
2 \\
34\end{array}$ \\
\hline
\end{tabular}

1

2
3

4

5
Title Page

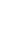




\section{6}

7

8

9

10

11

12

13

14

15

16

17

18

\section{ABSTRACT}

Background and Aims: Endoscopy and histopathology are pivotal for evaluating disease activity in ulcerative colitis (UC); correlation between validated endoscopic and histological indices has not been examined. We aim to correlate the Ulcerative Colitis Endoscopic Index of Severity (UCEIS) with two new validated histological indices in patients with established UC.

Methods: Retrospective single centre cohort of patients with established UC who underwent flexible sigmoidoscopy or colonoscopy by a single endoscopist. The UCEIS was scored at the worst affected area in the distal colon, which was biopsied; histological disease activity using Nancy (NI) and Robarts' Histological (RHI) indices was scored by a pathologist blinded to the endoscopy. Spearman correlation between the UCEIS, NI and RHI, and between NI and RHI were performed.

Results: 125 patients, median age 37 years (range 16-81 years), with UCEIS scores (scale 0-8) $0=21 ; 1-3=48 ; 4-6=51 ; 7-8=5$. Correlation coefficients between UCEIS and NI (scale $0-4)$ were $\mathrm{r}=0.84(95 \%$ CI $0.76-0.89, \mathrm{p}<0.001)$ and between UCEIS and RHI (scale 0-33) $\mathrm{r}=0.86(95 \% \mathrm{CI}$ $0.80-0.90, p<0.001)$. The difference in correlation was not significant $(\mathrm{p}=0.57)$. There was excellent correlation between the two histological indices ( $r=0.92,95 \%$ CI $0.87-0.95, \mathrm{p}<0.001)$. Quiescent disease activity defined as the absence of neutrophils (Nancy 0-1, Robarts 0-3) was most closely correlated with UCEIS $=0$.

Conclusions: The UCEIS strongly correlates with both NI and RHI. Complete mucosal healing is best defined as a $\mathrm{UCEIS}=0 / 8$, since this correlates with the absence of microscopic disease activity. 
30

31

32

33

34

\section{INTRODUCTION}

Therapeutic advances in the management of ulcerative colitis (UC) have changed treatment targets. $^{1-4}$ Mucosal healing is associated with improved clinical outcomes and is set to become a long term therapeutic goal. ${ }^{5-6}$ Endoscopic mucosal healing is defined by resolution of visible mucosal inflammation and ulceration at endoscopy. ${ }^{3}$ A Mayo Clinic endoscopic sub score (eMCS) has been associated with a higher rate of being corticosteroid free (eMCS 0 ) and lower rates of hospitalisation or colectomy (eMCS $\leq 1$ ) over a 12 month period. ${ }^{7-12}$ In a six year follow up study, concordance between endoscopic and histological remission was associated with better outcomes than endoscopic remission alone. ${ }^{13}$ Nevertheless, endoscopic mucosal healing does not necessarily reflect quiescent microscopic disease. ${ }^{14-15}$ Past attempts to correlate endoscopic activity and histological activity have been notable more for their disparity than correlation. ${ }^{16-19}$ The likely reason for this disparity is that there have been no validated endoscopic or histological indices to compare.

In the past three years, the situation has changed. The Ulcerative Colitis Endoscopic Index of Severity (UCEIS) is now validated in three independent cohorts. ${ }^{20-21}$ It accounts for $88 \%$ of the variation between observers and is unaffected by knowledge of clinical symptoms. ${ }^{22}$

Two validated histological indices were published in $2017 .{ }^{23-24}$ The Nancy Index (NI) consists of three components, with five grades of histological activity defined from grade 0 (absence of significant histological disease activity) to grade 4 (severely active disease). Intra-reader reliability was 0.88 (95\% CI 0.82-0.92) and the interclass correlation coefficient (ICC) for inter-reader reliability was 0.86 (95\% CI 0.81-0.99). ${ }^{23}$ The Robarts' Histopathology Index (RHI) uses similar descriptors, but breaks down acute inflammatory infiltrate into lamina propria and epithelial neutrophil components, so it has four components and a scale of 0 (no disease activity) to 33 (severe 
56 disease activity). Intra-rater and inter-rater ICCs were 0.92 (95\% CI 0.88-0.94) and 0.82 (95\% CI

$57 \quad 0.74-0.86)$ respectively. ${ }^{24}$

58

59 The primary aim of the current study was to correlate endoscopic (UCEIS) and histological (NI and

60 RHI) assessment of disease severity in UC using these validated indices. A secondary aim was to

61 determine whether a UCEIS of 0 or 1 best represents remission, based on the hypothesis that true

62 mucosal healing should best correlate with quiescent histopathology.

63 
64

65

66

67

68

69

70

71

72

73

74

75

76

77

78

79

80

81

82

83

84

85

86

87

88

\section{METHODS}

\subsection{Study design}

Single centre retrospective cohort study performed in between Oxford August 2015 to February 2016. Subjects enrolled had an established diagnosis of UC according to standard criteria. ${ }^{25}$ Patients with UC who had an endoscopic assessment by a single specialist (SPLT) between March 2013 and August 2015 were enrolled. Patients were excluded if they had colitis yet to be classified, Crohn's colitis, diversion, diverticular, infectious, drug-induced or ischaemic colitis, or an ileal pouch-anal anastomosis. Subjects were recruited regardless of the extent of clinical disease activity.

\subsection{Endoscopy}

Patients underwent a flexible sigmoidoscopy or colonoscopy according to standard technique by a single clinician (SPLT) and the UCEIS score (table 1) in the worst affected area in the distal colon was documented at the time of endoscopy. Biopsies were taken from worst affected area in addition to other areas as clinically indicated by the treating physician at the time of the endoscopy. The treating clinician (SPLT) was not blinded to the patients' clinical symptoms at the time of endoscopy, and some patients had multiple biopsies taken from varying colonic segments all during a single endoscopy at the treating clinician's discretion. Endoscopy reports were retrieved for procedures performed between March 2013 and August 2015 from the endoscopic reporting database 'Endobase'. Patients were excluded if a UCEIS score was not documented at the time of endoscopy or if biopsies were not taken for histology. Data were collected on the subject's age at time of endoscopy, gender, type of endoscopic procedure performed (flexible sigmoidoscopy or colonoscopy), date of procedure, UCEIS score and component sub-scores. To protect patient confidentiality, no patient names, initials, or date of birth were recorded on the same spreadsheet as the data collected. Study subjects were part of the "Inflammatory Bowel Disease in Oxford: 
89 prospective cohort for outcomes, treatment, and predictors" project, UK Research Ethics Committee 90 reference: 09/H1204/30.

91

92

\subsection{Histopathology}

93 The Nancy Index (NI, table 2) and the Robarts' Histopathology Index (RHI, table 3), were scored 94 by a single specialist gastrointestinal histopathologist (LMW), blinded to the subjects' clinical 95 information and endoscopic findings, using the worst affected area.

96

\section{$97 \quad 2.4$ Statistical Analysis}

98 Descriptive statistics, histograms and scatterplots were used for describing patient demographics, 99 distribution of UCEIS scores and histological indices. Spearman correlation between the UCEIS, 100 Nancy Index and Robarts Histological Index was performed, with a p-value of $<0.05$ used for 101 statistical significance. Confidence intervals for the Spearman correlation were obtained using 102 bootstrapping. A correlation coefficient (r) of zero indicates that no linear relationship exists 103 between two continuous variables, and a correlation coefficient of -1 or +1 indicates a perfect 104 linear relationship. If we wish to label the strength of the association, for absolute values of $\mathrm{r}, 0$ 1050.19 is regarded as very weak, 0.2-0.39 as weak, 0.40-0.59 as moderate, 0.6-0.79 as strong and 0.81061.0 as very strong correlation, but these are rather arbitrary limits, and the context of the results 107 should be considered. ${ }^{26}$ Analysis was performed using R version 3.2.3. 
108

109

110

111

112

113

114

115

116

117

118

119

120

121

122

123

124

125

126

127

128

129

130

131

\section{RESULTS}

\subsection{Patients}

A total of $126 \mathrm{UC}$ patients were identified. One patient was omitted from the final analysis because biopsies could not be located for histological assessment. Therefore 125 patients were included in the final analysis, with a median age of 37 years (range 16-81 years) at the time of endoscopy; 64/125 (51\%) were male. Baseline characteristics are shown in table 4.

\subsection{Endoscopy}

All UCEIS scores were represented, consistent with the full spectrum of disease activity (supplementary table 1). The UCEIS has been divided into four strata by some authors, to correlate with clinical activity: remission (UCEIS 0-1), mild (UCEIS 2-4), moderate (UCEIS 5-6) and severe (UCEIS 7-8). ${ }^{27}$ Nevertheless, debate continues whether 'remission' is best defined as UCEIS $=0$ or

$1 .^{28}$ It was assumed that UCEIS $=1$ in the remission stratum was a descriptor limited to partial obliteration of vascular pattern. Overall, 49/125 (39\%) patients had a UCEIS score of 0-1 and 42/125 (34\%) had mild colitis. A further 29/125 (23\%) had moderately active colitis and 5/125 (4\%) had severe colitis (figure 1).

\subsection{Histopathology}

All 5 grades of the Nancy Index were represented (supplementary figure 1). A total of 31\% (39/125) of patients had absence of histological disease, 36\% (45/125) mildly active disease, 4\% (5/125) moderately active disease and 22\% (28/125) severely active disease (supplementary table 2). 
132 Almost all levels of the Robarts Histopathology Index were represented (supplementary figure 2), 133 ranging from 0-31 with a median RHI score 10 and interquartile range 1-21 (supplementary table $1343)$.

135

136

137

\subsection{Correlation testing between endoscopy and histology scores}

The correlation coefficient between the UCEIS and NI was $\mathrm{r}=0.84(95 \%$ CI $0.76-0.89, \mathrm{p}<0.001)$. The correlation and confidence intervals (CI) between the UCEIS and RHI were similar: $\mathrm{r}=0.86$ $(95 \%$ CI $0.80-0.90, p<0.001)$. These correlations are classed as very strong given $r>0.8$. The NI and RHI histological indices were very strongly correlated: $r=0.92(95 \%$ CI $0.87-0.95, p<0.001)$. All correlations between the UCEIS, NI and RHI were statistically significant $p<0.001$, but the difference in correlation between the two histological indices was not $(p=0.57$, figure 2$)$.

\subsection{What level of UCEIS correlates with histological remission?}

Histological inactivity is defined by the absence of acute inflammation, neutrophils, erosions or ulceration, although a chronic inflammatory cell infiltrate may be present. Histological remission hence corresponds to a NI grade $\leq 1$ and an RHI score $\leq 3$, indicative of chronic inflammation but the absence of acute inflammatory changes.

To answer the question whether UCEIS $=0$ or UCEIS $=1$ best represents true remission, these UCEIS scores were evaluated against histological remission (NI grade $\leq 1$ or RHI score $\leq 3$ ). There were 21 patients with UCEIS=0, and 28 with a UCEIS=1 (all these only had partial obliteration of vascular pattern). $20 / 21(95 \%)$ patients with a $\mathrm{UCEIS}=0$ had an $\mathrm{NI}=0$ in contrast to $18 / 28(64 \%)$ patients with a UCEIS=1. The odds ratio (OR) was 11.1 (95\% CI 1.3-95.6, $\mathrm{p}=0.0143)$, indicating that

UCEIS $=0$ best matched NI grade 0 . With regard to NI=1, the same 20/21 (95\%) patients with a UCEIS $=0$ had also had NI grade $\leq 1$, compared to $20 / 28(71 \%)$ with a UCEIS $=1$; OR=8 $(95 \%$ CI 
157 0.9-70; $\mathrm{p}=0.059)$. With regard to RHI score $\leq 3,18 / 21(86 \%)$ with a UCEIS=0 had an $\mathrm{RHI} \leq 3$, 158 compared to $19 / 28(64 \%)$ with a UCEIS $=1$; OR=2.5 (95\% CI 0.6-11.1, $\mathrm{p}=0.304)$.

159

160 Since the trend favoured a UCEIS $=0$ to define endoscopic remission with histological remission, we

161 analysed a combined NI grade $\leq 1$ and RHI score $\leq 3$. When UCEIS=0, 18/21 (86\%) had a

162 combined NI and RHI indicating histological remission, compared to 18/28 (64\%) when UCEIS=1;

$163 \quad \mathrm{OR}=3.3(95 \%$ CI $0.8-14.2, \mathrm{p}=0.114)$.

164 
165

166

167

168

169

170

171

172

173

174

175

176

177

178

179

180

181

182

183

184

185

186

187

188

189

190

\section{DISCUSSION}

This is the first time that validated indices for endoscopy and histopathology have been correlated in ulcerative colitis and the results are novel. First, there was a very strong correlation between endoscopy and histopathology, in contrast to that reported with unvalidated indices. Second, there was also a very strong correlation between the two histopathology indices that have been validated for disease activity in ulcerative colitis. Third, the UCEIS score that best correlates with absence of histological disease activity is $0 / 8$ and this has prognostic implications.

Attempts to correlate endoscopic activity and histological activity in the past have been notable more for disparity than correlation. ${ }^{16-19,29}$ A plausible reason for this disparity is that there have, until now, been no validated endoscopic or histological indices to compare. When the Leuven group compared 263 biopsy sets from 131 patients with UC of differing activity ${ }^{19}$, comparing the eMCS with the Geboes ${ }^{30}$ and Riley ${ }^{31}$ histological indices, it was noted that endoscopically mildly active disease (Mayo 1) was distributed over all different histologic grades (37\% grade $0 ; 21 \%$ grade 1 ; $28 \%$ grade 2; and $14 \%$ grade 3 ). By comparing the 5 grade Nancy index (0-4) and the 9 grade UCEIS (0-8), we have shown that all correlations between the UCEIS and NI were highly statistically significant $(\mathrm{p}<0.001)$. When the disease was endoscopically mildly active (UCEIS 23/8), all patients with a UCEIS score of $3 / 8$ had a Nancy score of 2 and when the UCEIS was 2/8, then the Nancy score was 1 or 2 (figure 2). The same was true for correlations between the UCEIS and RHI, but the range was wider, consistent with the wider scale (RHI: 34 levels, 0-33). The overall correlation between the UCEIS and RHI was numerically greater $(r=0.86 ; 95 \%$ CI 0.80 $0.90, \mathrm{p}<0.001)$ than between the UCEIS and NI $(\mathrm{r}=0.84 ; 95 \%$ CI $0.76-0.89, \mathrm{p}<0.001)$, but the difference was not statistically significant. The full range of UCEIS scores was represented, which earlier work has shown correlates closely with the entire range of severity of UC, from normal to worst ever seen on a 100 point visual analogue scale. ${ }^{20}$ 
192 The two histopathology indices performed similarly well, as might be expected since the principal

193

194

195

196

197

198

199

200

201

202

203

204

205

206

207

208

209

210

211

212

213

214

215

difference between the two is that the RHI divides the acute inflammatory infiltrate of neutrophils into epithelial and lamina propria components, while the NI considers them together. Other components (chronic inflammatory infiltrate and ulceration) are the same, even if levels differ. The Nancy Index is considered (by our specialist GI pathologist, LMW) simpler to score in practice, but the close correlation means that either can be used confidently in clinical trials or clinical practice. The very strong correlation $(\mathrm{r}=0.92 ; 95 \% \mathrm{CI} 0.87-0.95, \mathrm{p}<0.001)$ is notable compared to studies of intraobserver and inter-observer variation for other indices. ${ }^{32}$ During the development of the Geboes Index for assessing disease activity, initial agreement on the assessment of 99 samples by three pathologists was too low to be of value with $\kappa$ values of $0.20,0.42$ and $0.26 .{ }^{30}$ Subsequent agreement after careful definition of terms, aided by pictograms, raised $\kappa$ values to $0.62,0.70$ and 0.59 , indicating modest to good agreement. No assessment was made of intra-observer variation. There was complete agreement between pathologists on neutrophil infiltration, which is a key component of both the NI and RHI. The Geboes Index, used in clinical trials was designed only to evaluate activity and not to be responsive, so has limited value in evaluating response to therapy. ${ }^{33}$ Response characteristics of the NI and RHI have been defined.

This study has also determined whether a UCEIS of 0 or $1 / 8$ represents remission, since this had not been evaluated during the development of the UCEIS ${ }^{20-21}$, even though others have speculated that it could be 0 or $1 .^{27-28}$ A UCEIS of $0 / 8$ is most closely correlated with histological remission. In this regard, 20/21 (95\%) patients with a UCEIS $=0$ had an NI=0, in contrast to $18 / 28(64 \%)$ patients with a UCEIS $=1$. This matters in clinical trials and practice. When the first biomarker of non-response to anti-TNF therapy was established in 2017 (Oncostatin M) the definition used to establish response (or non-response to anti-TNF therapy) was that of histological remission. ${ }^{34}$ Furthermore, histological 
216 remission when concordant with endoscopic and clinical remission, predicts better patient-related

217 outcomes with regard to steroid usage or hospitalisation than clinical and endoscopic remission

218 alone. ${ }^{13}$ Histopathology may yet prove the predictive biomarker that has eluded UC clinical trialists

219 and regulatory authorities.

220

221 There are, however, limitations to this study. It was, by its nature, retrospective and larger 222 prospective multi-centre studies are needed in the future to further corroborate our results.

223 Furthermore, the number of patients at the severe end of the spectrum (16/125, UCEIS 6-8/8) were

224 few. This matters less than it appears, since concordance between endoscopic and histological

225 disease activity matters most in mild-moderately active disease. In addition, only a single

226 endoscopist (SPLT) and a single specialist GI pathologist (LMW) were used to evaluate indices.

227 Apart from being a pragmatic approach, it can reasonably be argued that this reduced variation, 228 especially since SPLT led the development of the UCEIS, but we recognise the potential for bias.

229

230

231

232

233

What this study demonstrates is important for clinical practice, let alone trials. Very strong correlation between endoscopic and histological indices means that histopathology reports of activity when disease appears endoscopically inactive cannot be dismissed as aberrant, but requires attention to optimize (and potentially to escalate) treatment. Since histopathology reports arrive several days after endoscopy, it provides an opportunity to personalize therapy. The histopathologist can be confident that the Nancy and Robarts' Histological indices are as reliable as each other, even if the Nancy Index is simpler to score in practice. A UCEIS score $0 / 8$ best defines a target for complete mucosal healing with no histological disease activity. This predicts a good clinical outcome over succeeding years. 
240 Funding: The authors received no external funding for this work. Their institutional resources were 241 used to carry out this investigation.

242

243 Conflict of Interest: There is no financial conflict of interest to declare for any of the authors in 244 association with the publication of this manuscript.

245

246

247

248

249

250

251

252

253

254

255

256

Author Contributions: All authors had access to the study data. N. Irani, S. Travis and S. Keshav contributed to the study concept and design, data collection, data analysis and interpretation, and drafting of the manuscript. L.M. Wang and G. Collins contributed to the data collection, data analysis and interpretation, and drafting of the manuscript. All authors reviewed and approved the final version of the manuscript prior to submission.

Acknowledgements: We are most grateful to the patients who contributed to the study and our outstanding outpatient and endoscopy teams, as well as our clinical nurse specialists who helped coordinate the study. The research was supported by the National Institute for Health Research (NIHR) Oxford Biomedical Research Centre (BRC). The views expressed are those of the authors and not necessarily those of the NHS, the NIHR, or the Department of Health. 


\section{REFERENCES}

258 1. Abraham C, Cho JH. Inflammatory bowel disease. N Engl J Med 2009;361:2066-78.

259

260 2. D’Haens G, Sandborn WJ, Feagan BG, et al. A review of activity indices and efficacy end points 261 for clinical trials of medical therapy in adults with ulcerative colitis. Gastroenterology $262 \quad 2007 ; \mathbf{1 3 2}: 763-86$.

263

3. Travis SP, Higgins PD, Orchard T, et al. Review article: defining remission in ulcerative colitis. 265 Aliment Pharmacol Ther 2011;34(2):113-24.

266

267

4. Peyrin Biroulet L, Sands B, Reinisch W, et al. Selecting Therapeutic Targets in Inflammatory 268 Bowel Disease (STRIDE): determining therapeutic goals for treat-to-target. Am J Gastroenterol 269 2015;110(9):1324-38.

270

271

5. Bessissow T, Lemmens B, Ferrante M, et al. Prognostic value of serologic and histologic 272 markers on clinical relapse in ulcerative colitis patients with mucosal healing. Am J Gastroenterol $273 \quad 2012 ; 107: 1684-92$.

274

6. Neurath MF, Travis SP. Mucosal healing in inflammatory bowel diseases: a systematic review. 276 Gut 2012;61(11):1619-35.

277 278 279 280 281
7. Colombel JF, Rutgeerts $\mathrm{P}$, Reinisch W, et al. Early mucosal healing with Infliximab is associated with improved long-term clinical outcomes in ulcerative colitis. Gastroenterol 2011;141:11941201. 
282 8. Baert F, Moortgat L, Van Assche G, et al. Mucosal healing predicts sustained clinical remission 283 in patients with early-stage Crohn's disease. Gastroenterology 2010;138(2);463-8.

284

285

9. Rutgeerts P, Diamond RH, Bala M, et al. Scheduled maintenance treatment with infliximab is 286 superior to episodic treatment for healing of mucosal ulceration associated with Crohn's disease. Gastrointest Endosc 2006;63(3):433-42.

10. D’Haens G, Baert F, Van Assche G, et al. Early combined immunosuppression or conventional management in patients with newly diagnosed Crohn's disease: an open randomized trial. Lancet 291 2008;371(9613):660-7.

292

293

11. De Cruz P, Kamm MA, Prideaux L, et al. Mucosal healing in Crohn's disease: a systematic review. Inflamm Bowel Dis 2013;19(2);429-44.

12. Schnitzler F, Fidder H, Ferrante M, et al. Mucosal healing predicts long term outcome of maintenance therapy with infliximab in Crohn's disease. Inflamm Bowel Dis 2009;15(9):1295-301.

298

299

13. Bryant RV, Burger DC, Delo J, et al. Beyond endoscopic mucosal healing in UC: histological 300 remission better predicts corticosteroid use and hospitalization over 6 years of follow-up. Gut 301 2016;65:408-414.

302

14. Korelitz BI. Mucosal healing as an index of colitis activity: back to histological healing for 304 future indices. Inflamm Bowel Dis 2010;16(9);1628-30. ulcerative colitis in clinical remission. Clin Gastroenterol Hepatol 2013;11(8):991-6. 
308

309

310

311

312

313

314

315

316

317

318

319

320

321

322

323

324

325

326

327

328

329

330

331

332

333

16. Powell-Tuck J, Day DW, Buckell NA, et al. Correlations between defined sigmoidoscopic appearances and other measures of disease activity in ulcerative colitis. Dig Dis Sci 1982;27:533-7.

17. Gomes P, du Boulay C, Smith CL, et al. Relationship between disease activity indices and colonoscopic findings in patients with colonic inflammatory bowel disease. Gut 1986;27:92-5.

18. Bessho R, Kanai T, Hosoe N, et al. Correlation between endocytoscopy and conventional histopathology in microstructural features of ulcerative colitis. J Gastroenterol 2011;46:1197-202.

19. Lemmens B, Arijs I, Van Assche G, et al. Correlation between the endoscopic and histologic score in assessing the activity of ulcerative colitis. Inflamm Bowel Dis 2013;19:1194-201.

20. Travis SP, Schnell D, Krzeski P, et al. Developing an instrument to assess the endoscopic severity of ulcerative colitis: the Ulcerative Colitis Endoscopic Index of Severity (UCEIS). Gut 2012;61(4):535-42.

21. Travis SP, Schnell D, Krzeski P, et al. Reliability and initial validation of the Ulcerative Colitis Endoscopic Index of Severity (UCEIS). Gastroenterol 2013;145(5):987-95.

22. Travis SP, Schnell D, Feagan BG, et al. The impact of clinical information on the assessment of endoscopic activity: characteristics of the Ulcerative Colitis Endoscopic Index of Severity (UCEIS). J Crohn's Colitis 2015;9(8):607-16.

23. Marchal-Bressenot A, Salleron J, Boulagnon-Rombi C, et al. Development and validation of the Nancy histological index for UC. Gut 2017;66(1):43-49. 
334

335

336

337

338

339

340

341

342

343

344

345

346

347

348

349

350

351

352

353

354

355

356

357

24. Mosli MH, Feagan BG, Zou G, et al. Development and validation of a histological index for UC. Gut 2017;66(1):50-58.

25. Dignass A, Eliakim R, Magro F, et al. Second European evidence-based consensus on the diagnosis and management of ulcerative colitis part 1: definitions and diagnosis. J Crohn's Colitis 2012;6:965-90.

26. Brown RA, Swanson-Beck J. Medical Statistics on Personal Computers, 2nd edn. London: BMJ Publishing Group, 1993.

27. Ikeya K, Hanai H, Sugimoto K, et al. The Ulcerative Colitis Endoscopic Index of Severity more accurately reflects clinical outcomes and long-term prognosis than the Mayo Endoscopic Score. $J$ Crohn's Colitis 2016;10(3):286-95.

28. Vuitton L, Marteau P, Sandborn WJ, et al. Defining endoscopic response and remission in ulcerative colitis clinical trials: an international consensus. Aliment Pharmacol Ther 2017;45:80113.

29. Fluxá D, Simian D, Flores L et al. Clinical, endoscopic and histological correlation and measures of association in ulcerative colitis. J Dig Dis 2017;18:634-41.

30. Geboes K, Riddell R, Ost A, et al. A reproducible grading scale for histological assessment of inflammation in ulcerative colitis. Gut 2000;47(3):404-9. 
359 31. Riley SA, Mani V, Goodman MJ, et al. Microscopic activity in ulcerative colitis: what does it 360 mean? Gut 1991;32(2);174-8.

362 32. Langner C, Magro F, Driessen A, et al. The histopathological approach to inflammatory bowel 363 disease: a practice guide. Virchows Arch 2014:464(5):511-27.

364

365 33. Bryant R, Weiner S, Travis SPL et al. Systematic review: histological remission in

366 inflammatory bowel disease. Is 'complete' remission the new treatment paradigm? An IOIBD

367 initiative. J Crohns Colitis 2014;8:1582-97.

368

369 34. West NR, Hegazy AN, Owens BMJ, et al. Oncostatin-M drives intestinal inflammation in mice

370 and its abundance predicts response to anti-tumour necrosis factor neutralizing therapy in patients

371 with inflammatory bowel disease. Nature Medicine 2017;23:579-89.

372 


\section{FIGURE LEGENDS}

374 Figure 1: Distribution of total UCEIS scores.

375 Figure 2: Distribution, scatterplot and correlation coefficient (r) between UCEIS, NI and RHI.

376

377

378

a) UCEIS \& RHI (scale 0-33): $\mathrm{r}=0.86,95 \%$ CI 0.80-0.90, $\mathrm{p}<0.001$

b) UCEIS \& NI (scale 0-4): r=0.84, 95\% CI 0.76-0.89, $\mathrm{p}<0.001$

c) RHI \& NI: $r=0.92,95 \%$ CI $0.87-0.95, p<0.001$

379

380 Supplementary Figure 1: Distribution of Nancy Index scores.

381 Supplementary Figure 2: Distribution of Robarts Histologic Index scores. 


\section{TABLES}

384 Table 1: UCEIS descriptors, levels and definitions used for evaluating UC.

\begin{tabular}{|c|c|c|}
\hline Descriptor & Score (points) & Definition \\
\hline \multirow[t]{3}{*}{ Vascular Pattern } & Normal (0) & Normal vascular pattern \\
\hline & Patchy obliteration (1) & Patchy obliteration of vascular pattern \\
\hline & Obliterated (2) & Complete obliteration of vascular pattern \\
\hline \multirow[t]{4}{*}{ Bleeding } & None $(0)$ & No visible blood \\
\hline & Mucosal (1) & $\begin{array}{l}\text { Spots or streaks of coagulated blood on the } \\
\text { mucosal surface which can be washed away }\end{array}$ \\
\hline & Luminal mild (2) & Some free liquid blood in the lumen \\
\hline & $\begin{array}{l}\text { Luminal moderate or } \\
\text { severe (3) }\end{array}$ & $\begin{array}{l}\text { Visible oozing of blood from haemorrhagic } \\
\text { mucosa }\end{array}$ \\
\hline \multirow[t]{4}{*}{ Erosions \& Ulcers } & None $(0)$ & Normal mucosa, no visible erosions or ulcers \\
\hline & Erosions (1) & $\begin{array}{l}\text { Tiny }(\leq 5 \mathrm{~mm}) \text { defects in the mucosa, of a white or } \\
\text { yellow colour with a flat edge }\end{array}$ \\
\hline & Superficial ulcer (2) & $\begin{array}{l}\text { Larger }(>5 \mathrm{~mm}) \text { defects in the mucosa, which are } \\
\text { discrete fibrin covered ulcers, but remain } \\
\text { superficial }\end{array}$ \\
\hline & Deep ulcer (3) & $\begin{array}{l}\text { Deeper excavated ulcers in the mucosa, with a } \\
\text { slightly raised edge }\end{array}$ \\
\hline
\end{tabular}




\section{1}

2

3

4

5

6

7

8

9

10

11

387 Table 2: Description of the Nancy Index histological criteria and definitions.

\begin{tabular}{|c|c|c|c|}
\hline Grade & $\begin{array}{l}\text { Acute inflammatory cell } \\
\text { infiltrate }\end{array}$ & $\begin{array}{l}\text { Chronic inflammatory cell } \\
\text { infiltrate }\end{array}$ & Ulceration \\
\hline 0 & None (0 point) & $\begin{array}{l}\text { None ( } 0 \text { point }) \\
\text { Mild ( } 1 \text { point })\end{array}$ & None (0 point) \\
\hline 1 & None (0 point) & $\begin{array}{l}\text { Moderate or marked increase } \\
\text { ( } 3 \text { points) }\end{array}$ & None (0 point) \\
\hline 2 & Mild (2 points) & $\begin{array}{l}\text { Moderate or marked increase } \\
\text { ( } 3 \text { points) }\end{array}$ & None (0 point) \\
\hline 3 & $\begin{array}{l}\text { Moderate ( } 3 \text { points) } \\
\text { Severe ( } 4 \text { points })\end{array}$ & $\begin{array}{l}\text { Moderate or marked increase } \\
\text { ( } 3 \text { points) }\end{array}$ & None (0 point) \\
\hline 4 & $\begin{array}{l}\text { Moderate ( } 3 \text { points) } \\
\text { Severe ( } 4 \text { points) }\end{array}$ & $\begin{array}{l}\text { Moderate or marked increase } \\
\text { ( } 3 \text { points) }\end{array}$ & Yes ( 2 points $)$ \\
\hline
\end{tabular}


390 Table 3: Components of the Robarts' Histopathology Index.

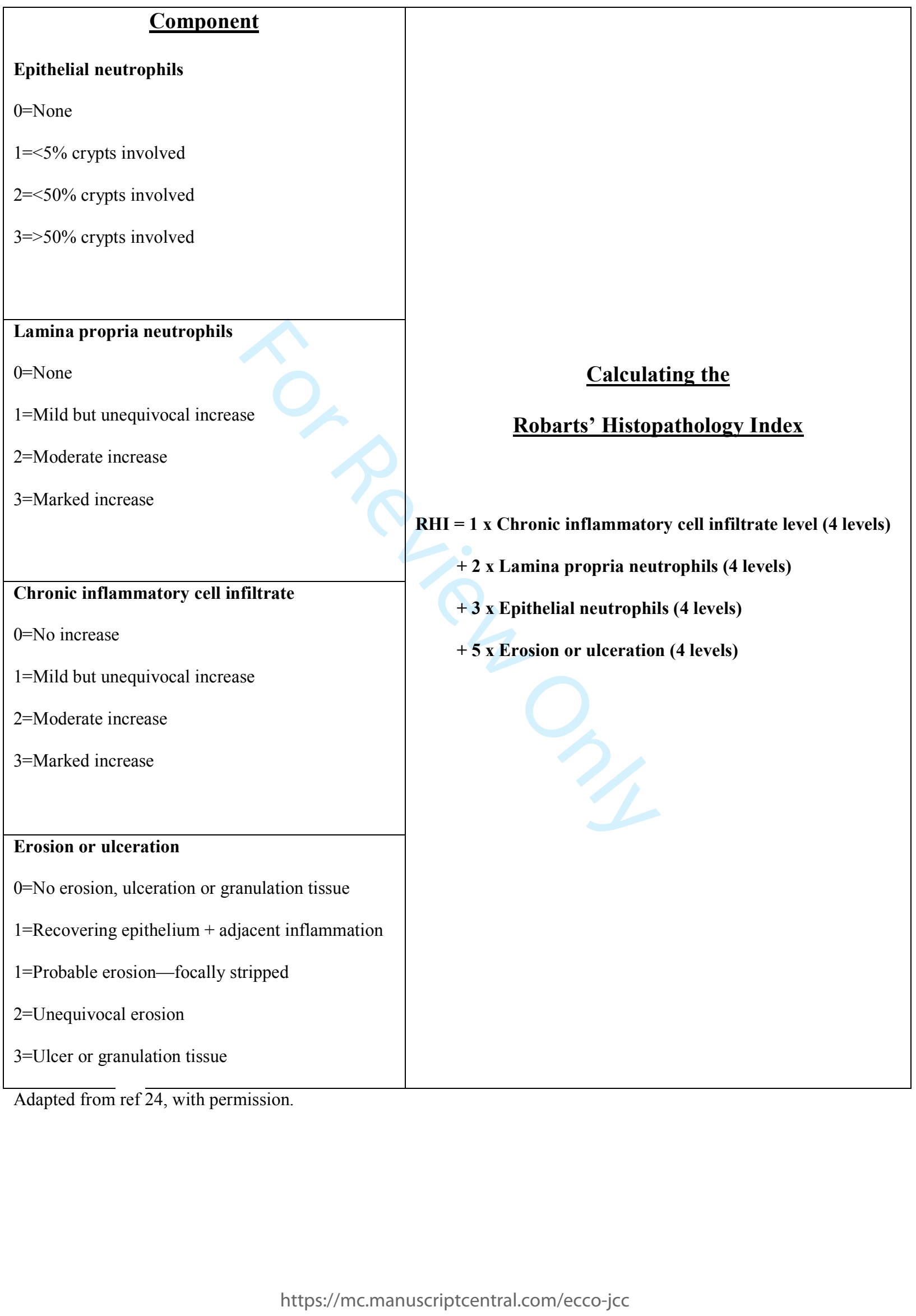


393 Table 4: Baseline characteristics of patients with UC (n and \% unless specified).

\begin{tabular}{|c|c|}
\hline Baseline characteristics & n (\%) \\
\hline Patients with UC & 125 \\
\hline Age (years), mean (sd) & $39.2(15)$ \\
\hline \multicolumn{2}{|l|}{ Sex } \\
\hline Men & $64(51)$ \\
\hline Women & $61(49)$ \\
\hline \multicolumn{2}{|l|}{ Procedure } \\
\hline Flexible sigmoidoscopy & $76(61)$ \\
\hline Colonoscopy & $49(39)$ \\
\hline \multicolumn{2}{|l|}{ Number of biopsies taken per patient } \\
\hline 1 & $4(3)$ \\
\hline 2 & $46(36)$ \\
\hline 3 & $21(17)$ \\
\hline 4 & $14(11)$ \\
\hline 5 & $21(17)$ \\
\hline 6 & $12(10)$ \\
\hline 7 & $5(4)$ \\
\hline 8 & $2(2)$ \\
\hline
\end{tabular}




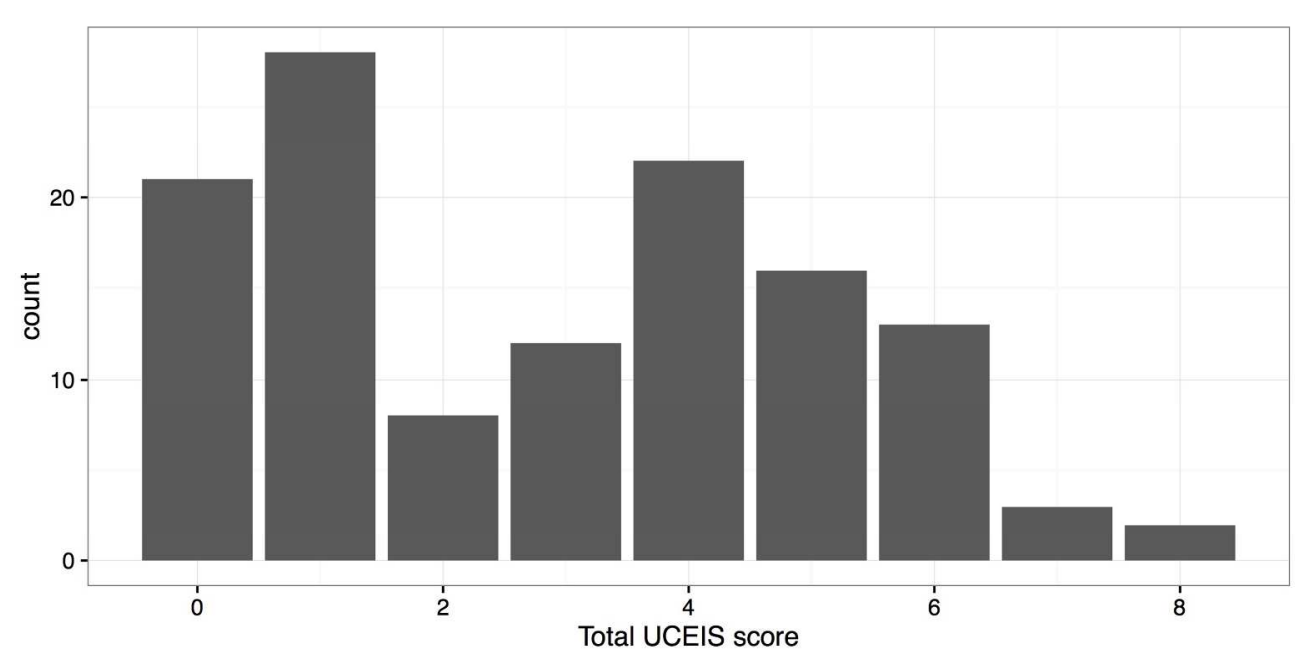

Figure 1: Distribution of total UCEIS scores.

$203 \times 101 \mathrm{~mm}(300 \times 300$ DPI) 

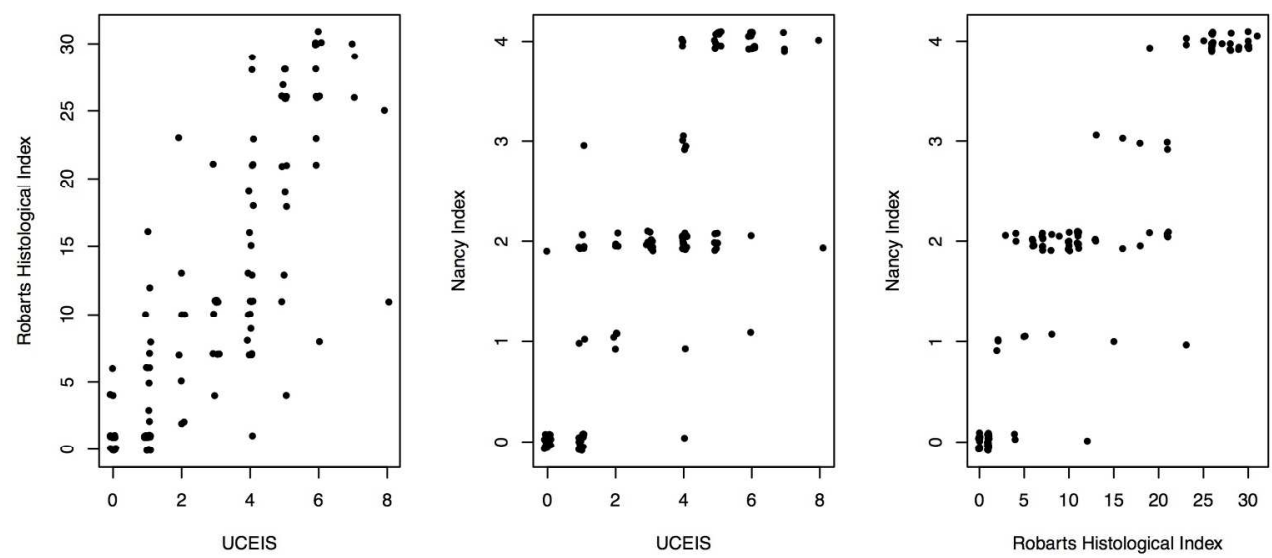

Figure 2: Distribution, scatterplot and correlation coefficient ( $r$ ) between UCEIS, NI and RHI.

a) UCEIS \& RHI (scale 0-33): $r=0.86,95 \%$ CI $0.80-0.90, p<0.001$

b) UCEIS \& NI (scale 0-4): r=0.84, 95\% CI 0.76-0.89, $p<0.001$

c) RHI \& NI: $r=0.92,95 \%$ CI $0.87-0.95, p<0.001$

$203 \times 101 \mathrm{~mm}(300 \times 300 \mathrm{DPI})$ 


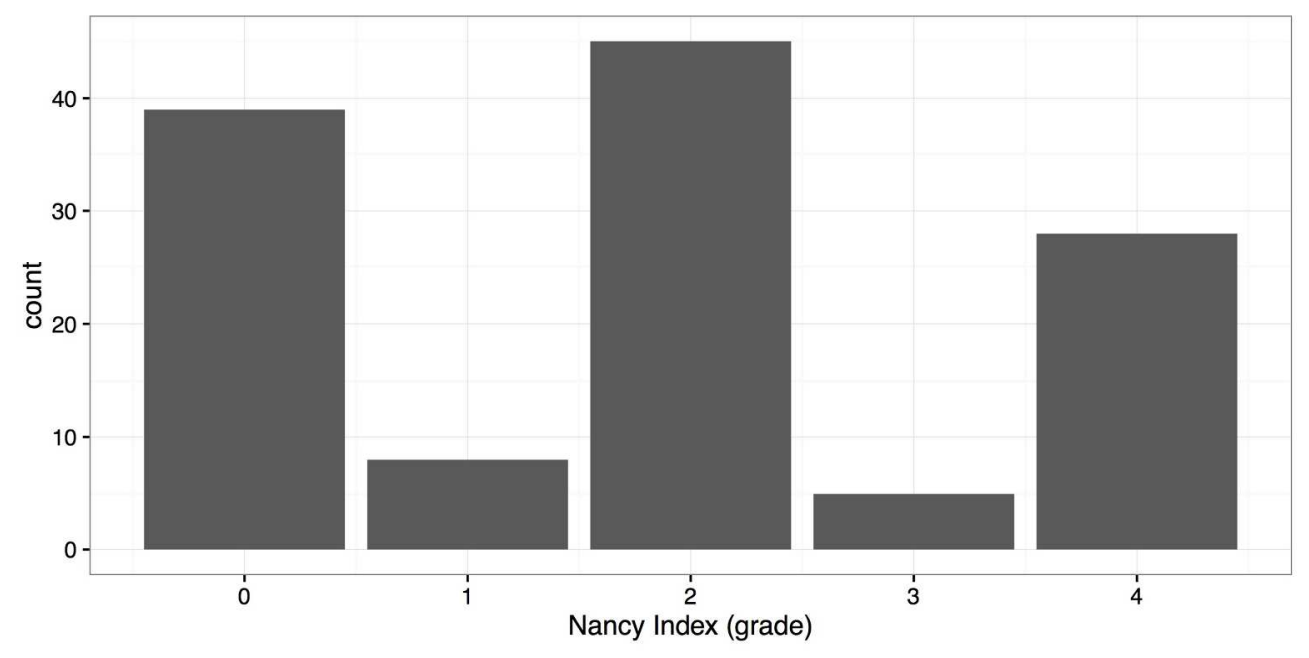

$203 \times 101 \mathrm{~mm}(300 \times 300 \mathrm{DPI})$ 


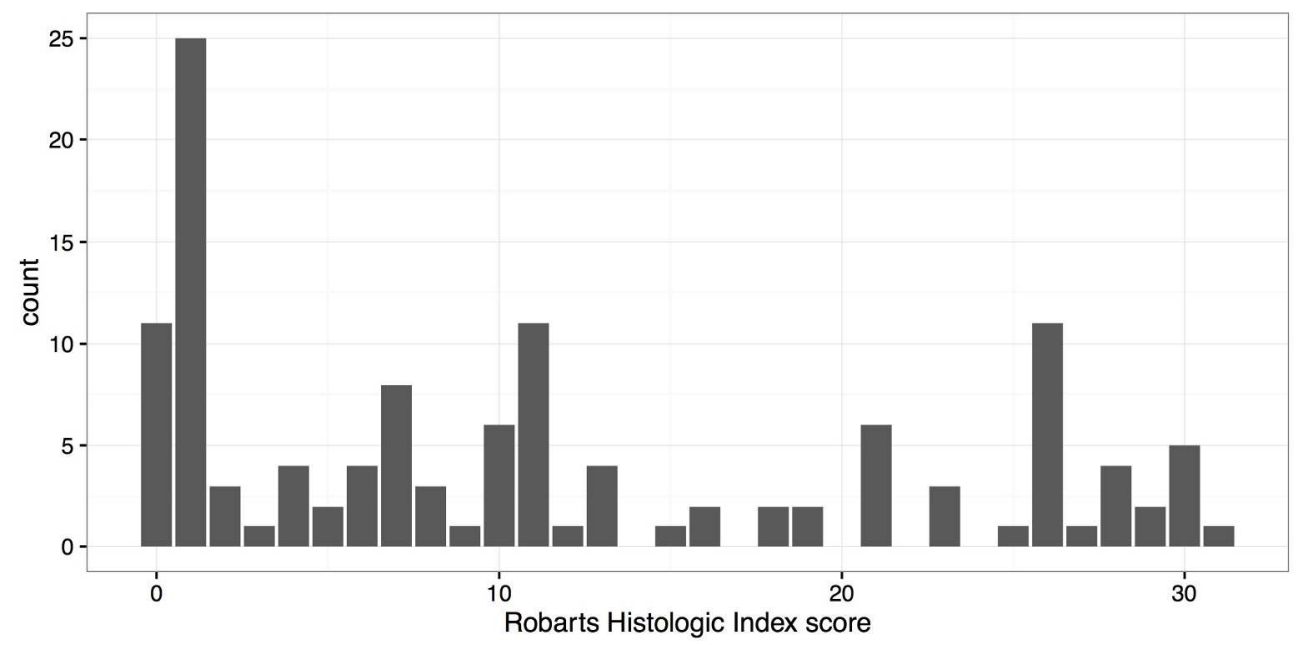

$203 \times 101 \mathrm{~mm}(300 \times 300 \mathrm{DPI})$ 


\section{SUPPLEMENTARY MATERIAL TABLES}

Supplementary Table 1: Range of UCEIS scores according to individual components.

\begin{tabular}{|c|c|}
\hline Component & n (\%) \\
\hline \multicolumn{2}{|l|}{ Vascular pattern } \\
\hline Normal & $21(17)$ \\
\hline Patchy obliteration & $34(27)$ \\
\hline Obliterated & $70(56)$ \\
\hline \multicolumn{2}{|l|}{ Bleeding } \\
\hline None & $63(50)$ \\
\hline Mucosal & $44(36)$ \\
\hline Luminal mild & $14(11)$ \\
\hline Luminal moderate or severe & $4(3)$ \\
\hline \multicolumn{2}{|l|}{ Ulceration \& Erosions } \\
\hline None & $61(50)$ \\
\hline Erosions $5 \mathrm{~mm}$ or less & $28(22)$ \\
\hline Superficial ulcer $>5 \mathrm{~mm}$ & $31(25)$ \\
\hline Deep ulcer & $5(4)$ \\
\hline \multicolumn{2}{|l|}{ Total UCEIS score } \\
\hline 0 & $21(17)$ \\
\hline 1 & $28(22)$ \\
\hline 2 & $8(6)$ \\
\hline 3 & $12(10)$ \\
\hline 4 & $22(18)$ \\
\hline
\end{tabular}




\begin{tabular}{|c|c|}
\hline 5 & $16(13)$ \\
\hline 6 & $13(10)$ \\
\hline 7 & $3(2)$ \\
\hline 8 & $2(2)$ \\
\hline
\end{tabular}

Supplementary Table 2: Nancy Index range of scores.

\begin{tabular}{|c|c|}
\hline Item & n $(\%)$ \\
\hline \multicolumn{2}{|l|}{ Acute inflammatory cell infiltrate } \\
\hline None & $47(37.6)$ \\
\hline Mild & $62(49.6)$ \\
\hline Moderate & $12(9.6)$ \\
\hline Severe & $4(3.2)$ \\
\hline \multicolumn{2}{|c|}{ Chronic inflammatory cell infiltrate } \\
\hline None & $11(8.8)$ \\
\hline Mild & $34(27.2)$ \\
\hline Moderate or marked increase & $28(22.4)$ \\
\hline Severe & $52(41.6)$ \\
\hline \multicolumn{2}{|l|}{ Ulceration } \\
\hline None & $97(77.6)$ \\
\hline Yes & $28(22.4)$ \\
\hline \multicolumn{2}{|l|}{ Grade } \\
\hline 0 & $39(31.2)$ \\
\hline 1 & $8(6.4)$ \\
\hline 2 & $45(36.0)$ \\
\hline
\end{tabular}




\begin{tabular}{|l|c|}
\hline 3 & $5(4.0)$ \\
\hline 4 & $28(22.4)$ \\
\hline
\end{tabular}

Supplementary table 3: Robarts' Histopathology Index range of scores.

\begin{tabular}{|l|c|}
\hline Item & n (\%) \\
\hline Epithelial neutrophils & \\
\hline None & $43(34)$ \\
\hline$<5 \%$ crypts involved & $27(22)$ \\
\hline$<50 \%$ crypts involved & $45(36)$ \\
\hline$>50 \%$ crypts involved & $10(8)$ \\
\hline Lamina propria neutrophils & $46(37)$ \\
\hline No increase & $64(51)$ \\
\hline Mild but unequivocal increase & $11(9)$ \\
\hline Moderate increase & $4(3)$ \\
\hline Marked increase & $28(22)$ \\
\hline Chronic inflammatory cell infiltrate & $52(42)$ \\
\hline No increase & $11(9)$ \\
\hline Mild but unequivocal increase & \\
\hline Moderate increase & \\
\hline Marked increase & \\
\hline Erosion or ulceration & \\
\hline No erosion, ulceration or granulation tissue \\
\hline Recovering epithelium + adjacent inflammation \\
\hline orobly erosion-focally stripped
\end{tabular}




\begin{tabular}{|l|c|}
\hline Unequivocal erosion & $6(5)$ \\
\hline Ulcer or granulation tissue & $29(23)$ \\
\hline Robarts' Histologic Index (0-33) & \\
\hline Mean (sd) & $11.4(10)$ \\
\hline Median (IQR) & $10(1,21)$ \\
\hline (minimum, maximum) & $(0,31)$ \\
\hline
\end{tabular}

